\title{
MICRO-FLEX MIRROR AND INSTABILITY ACTUATION TECHNIQUE
}

\author{
Ernest J. Garcia \\ Electromechanical Engineering Department \\ Sandia National Laboratories \\ Albuquerque, NM, 87185-0329 USA
}

\begin{abstract}
This paper reports on the design and fabrication of a surface micromachined mirror system which is capable of producing the required moments to rotate a mirror structure out of the plane of fabrication. The planar structures created by surface micromachining present difficulties with developing a sufficient moment to move structures out of the $x-y$ plane when actuated by those same planar structures. This is due to the short moment arms (in thickness direction $\mathrm{z}$ ) that can be created in the fabrication process. The instability actuation technique reported here has general application to moving 2-dimensional structures up and out of the plane of their original fabrication. This technique can be applied to "build" truly 3-dimensional structures from a nearly 2dimensional fabrication process. Surface micromachining can now be considered a 3dimensional process where 3-dimensional structures are built by raising up structures by the instability actuation technique and making appropriate mechanical interconnections.
\end{abstract}

\section{INTRODUCTION}

An entirely different procedure for raising structures out of plane has been successfully demonstrated. Problems due to the inherently small moment arms that can be produced in surface micromachined planar structures are completely circumvented. In this procedure, a part of the system is "buckled" upward by applying an axial force large enough to buckle an element such as a beam. The "buckled" beam element is designed to move up and off the surface of the substrate as shown in the scanning electron micrograph (SEM) of an actuated micro-flex mirror, Figure 1. The buckled form of the beam produces a bending moment about an axis of bending which is parallel with the substrate plane. This moment, present in the buckled beam configuration,

\section{DIBTRBBUTION OF THIS DOCUMENT IS UNMMTEO}

is used to raise a mirror or other structure out of the original plane of fabrication.

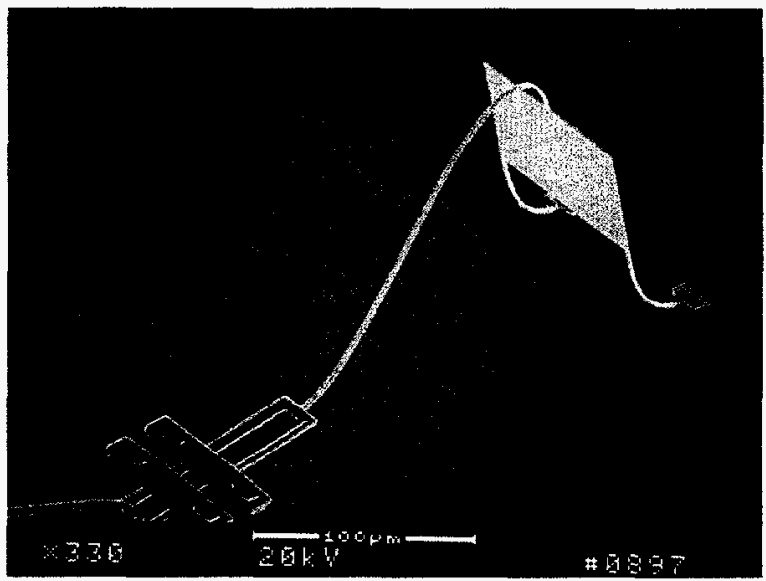

Figure 1 Actuated Micro-Flex Mirror

\section{MICROMIRRORS}

An important area of application for this actuation technique is in micro-optics. In contrast to micromirror devices [1] that move or tilt slightly, there are situations where it is desired to move a micromirror significantly out of the plane of fabrication. Such is the case for an optical beam directed parallel to the substrate surface and located a given distance above the substrate that must be redirected $90^{\circ}$ or more. Figure 2 shows an optical switching device which must redirect the input beam through large angles to one of several receptor locations.

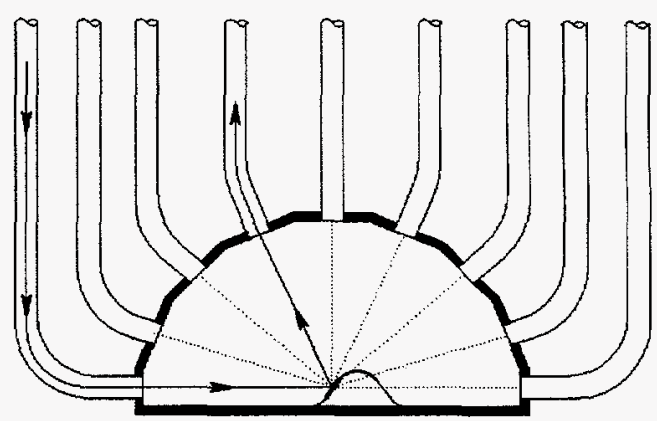

Figure 2 Fiber Optic Switching Device 


\section{DISclanmiex}

Portions of this docament may be illegible in electronic image produets. Images are produced from the best arailable original doecoment 


\section{DISCLAIMER}

This report was prepared as an account of work sponsored by an agency of the United States Government. Neither the United States Government nor any agency thereof, nor any of their employees, makes any warranty, express or implied, or assumes any legal liability or responsibility for the accuracy, completeness, or usefulness of any information, apparatus, product, or process disclosed, or represents that its use would not infringe privately owned rights. Reference herein to any specific commercial product, process, or service by trade name, trademark, manufacturer, or otherwise does not necessarily constitute or imply its endorsement, recommendation, or favoring by the United States Government or any agency thereof. The views and opinions of authors expressed herein do not necessarily state or reflect those of the United States Government or any agency thereof. 
A folding micromirror $[2,3]$ driven by an impact-type actuator has been previously demonstrated. However, folding mirror arrangements can sometimes exhibit difficulties with raising the mirror out of plane. In those instances, the mirror must first be "started" manually with a probe tip. A system that can repeatably operate without dependence on small moment arms is desired. The instability actuation technique offers one such solution.

\section{ACTUATION PRINCIPLE}

Studies of the stability of physical systems started with Euler who in 1744 determined, through his own development of variational methods, the equilibrium configurations of a compressed elastic column. Later developments by Lagrange, published in 1788, produced an energy theorem that showed the stability of a conservative system depends on a minimum of the total potential energy. Many individuals have contributed to the stability of physical systems including H. Poincare, A. Liapunov, E. Trefftz, W. Koiter, and myriad others. The ubiquitous nature of beam, plate, and shell structures has led to extensive investigations of the stability of these structures by many of the great mechanicians. Studies of the stability of physical systems have been extended to such diverse topics as astrophysics, biology, ecology, and aerodynamics to name but a few.

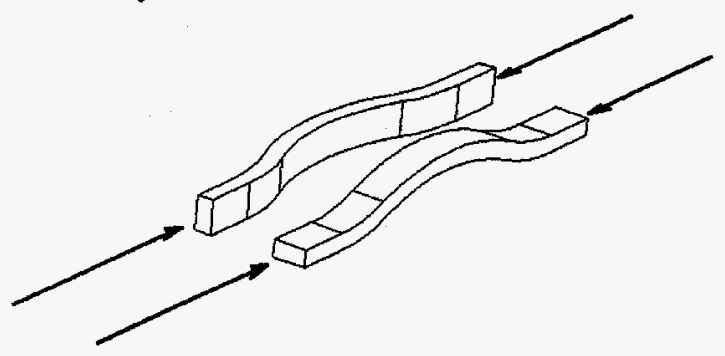

Figure 3 Buckling Configurations

In structural mechanics the stability of structures has usually been examined from the point of view of eliminating the onset of instability since buckling normally resulted in catastrophic consequences. Our interest is the converse; we wish to design structural systems that will "buckle" upon application of a specified input force with a resulting large change in system configuration. Application of the instability actuation technique to micro electro mechanical systems is particularly advantageous since many of the devices fabricated tend to be planar structures. This method allows us to use a force generated entirely within the fabricated planar structure $(x-y$ plane), and acting in directions within the $x-y$ plane, to produce motion normal to the $\mathrm{x}-\mathrm{y}$ plane, i.e., in the z-direction. Hence, a properly designed beam element can be used as an actuator to produce large motions normal to the original plane of fabrication. Figure 3 shows two beam elements both restrained to prevent rotation at each end (designated as fixedfixed or clamped-clamped) and the direction they will deform upon application of a suitable buckling force.

The buckling of structures is examined in many texts $[4,5]$. There are several methods used to determine the critical buckling load. The most direct uses a linear analysis to examine the differential equation of equilibrium to determine characteristic values or eigenvalues which tend to make the deflections go to infinity. The energy method concerns itself with the determination of a relative minimum of a total potential energy function for the system. For a system such as the micro-flex mirror, which consists of several discrete parts, the energy method tends to facilitate the calculation of the onset of buckling. The configuration of the post-buckled state has been investigated by energy methods and direct examination of the equilibrium equations. Extensive information is available in the literature [6], including a discussion of the post-buckling configuration of micromachined beams [7].

\section{MICRO-FLEX MIRROR DESIGN}

The micro-flex mirror system consists of 3 major parts; the driver, a linkage system used to amplify the input force, and the mirror/flexure element.

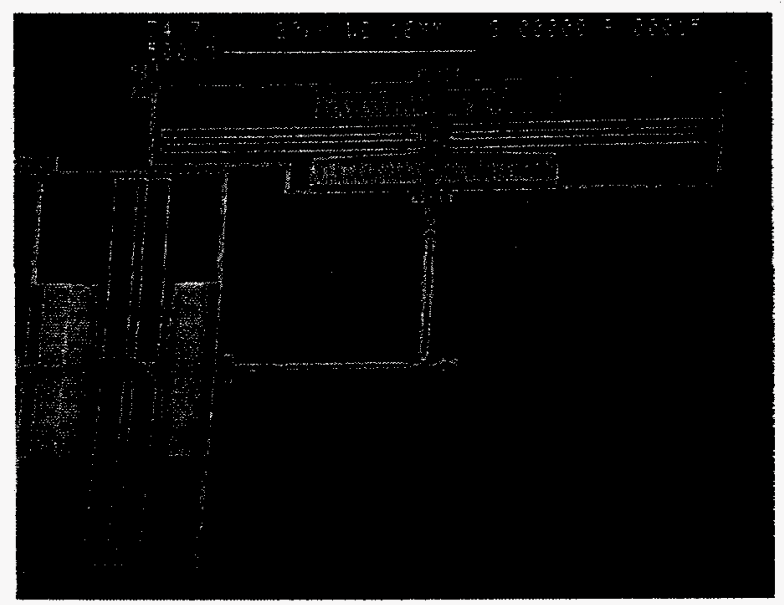

Figure 4 Surface Micromachined Microengine

The actuator used is the surface micromachined microengine [8] which is a general purpose actuator 
that has been used for driving a variety of geared systems. Figure 4 shows an intermediate view of the microengine. This device uses electrostatic combdrive actuators to turn an output gear through a linkage arrangement.

For the micro-flex mirror system, the output gear of the microengine drives a geared linkage system that has been designed to provide high initial forces to the mirror elements. Figure 5 is a schematic of the linkage system. Note that in the start position the line of action of the drive link passes directly over the pivot point of the segmented gear, hence $h$ in Figure 5 is zero.

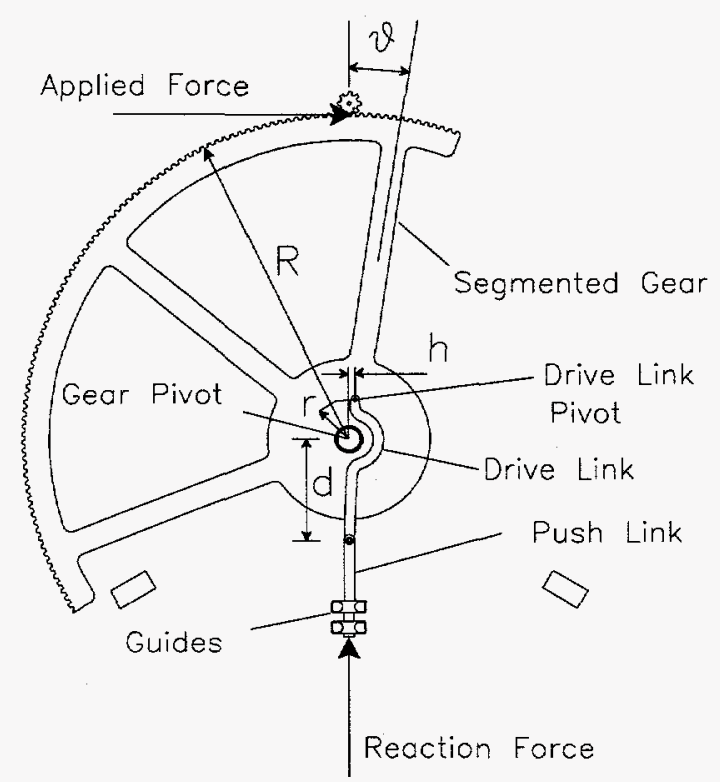

Figure 5 Linkage System for Force Amplification

Neglecting friction, equation (1) gives the relationship for drive link output force and input force as a function of segmented gear angle $\theta$ and the other linkage parameters $r$ and $R$ as given in Figure 6.

$$
\frac{F_{\text {Reaction }}}{F_{\text {Applied }}}=\frac{R}{r \sin (\theta)} \frac{1}{\left.1-\frac{r \cos (\theta)}{(r+d) \sqrt{1-(r /(r+d))^{2} \sin ^{2}(\theta)}}\right)}
$$

Subtracting a term from $F_{\text {Reaction }}$ equal to the coefficient of friction $\mu$ times the normal force $\mathrm{N}$ yields a corrected value for the force available for actuation $F_{R_{f}}$ given by equation (2).

$$
\begin{aligned}
\frac{F_{R_{f}}}{F_{\text {Applied }}}= & \frac{R}{r \sin (\theta)} \frac{1}{\left(1-\frac{r \cos (\theta)}{(r+d) \sqrt{1-(r /(r+d))^{2} \sin ^{2}(\theta)}}\right)} \times \\
& \left(1-\mu \frac{(r /(r+d)) \sin (\theta)}{\sqrt{1-(r /(r+d))^{2} \sin ^{2}(\theta)}}\right)
\end{aligned}
$$

Figure 6 shows the force relationship as a function of angular position of the segmented gear for an input torque of $20 \mathrm{pN}-\mathrm{m}$ delivered by the microengine and a coefficient of friction $\mu=0.3$. As the segmented gear rotates, the pusher link, which is held in position by guides, applies a force to the mirror flexure element.

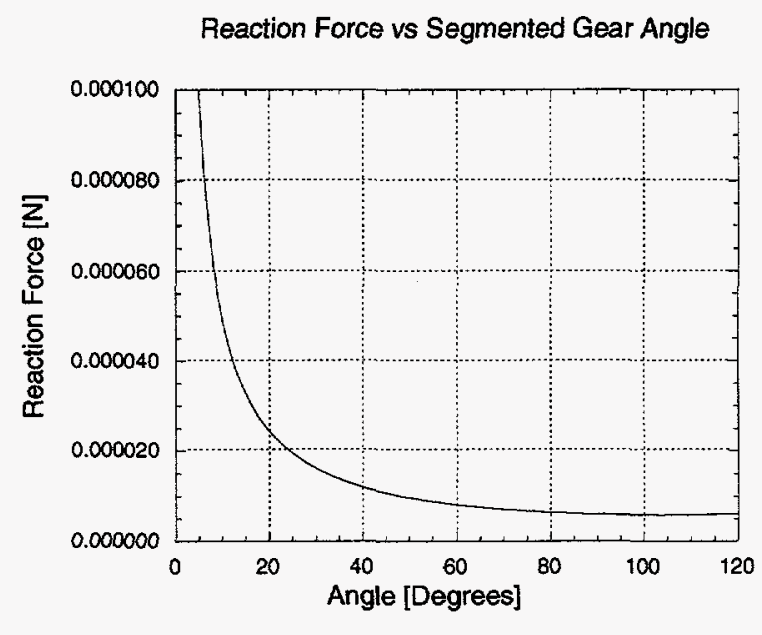

Figure 6 Actuator Output Force

Figure 7 illustrates the micro-mirror actuation sequence as force is applied by the pusher link. As force is applied, the flexure element deforms either upwards, or downwards towards the substrate. Initially the flexure element may move downwards toward the substrate since there is a slight gap between the flexure element in its original position and the substrate surface. However, after contact with the substrate surface, the flexure will finally deform up and away from the substrate surface since additional buckling occurs from this position. When the flexure element buckles, a bending moment exists in this curved beam element which is transferred to the mirror. The application of this moment to the mirror results in the mirror rotating upwards into the desired actuated position. 


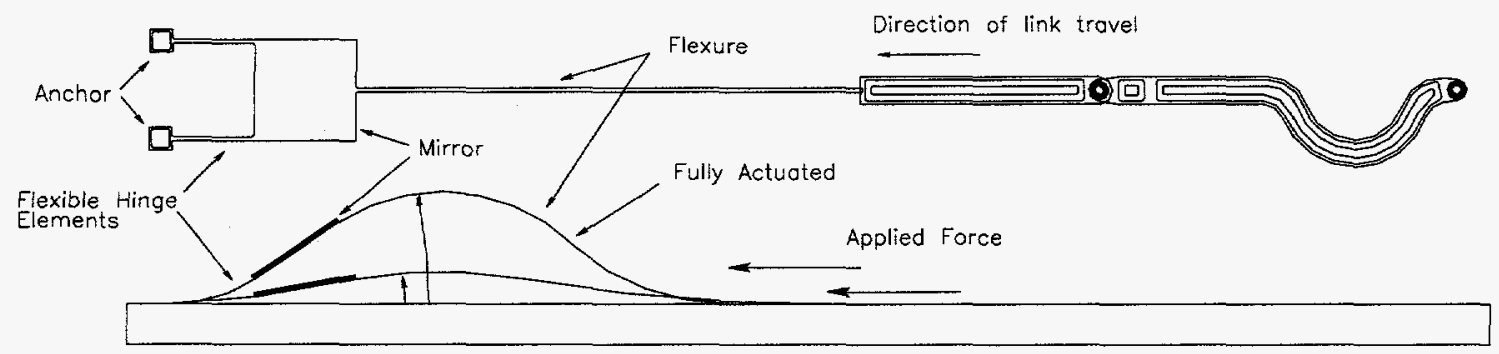

Figure 7 Actuation Schematic

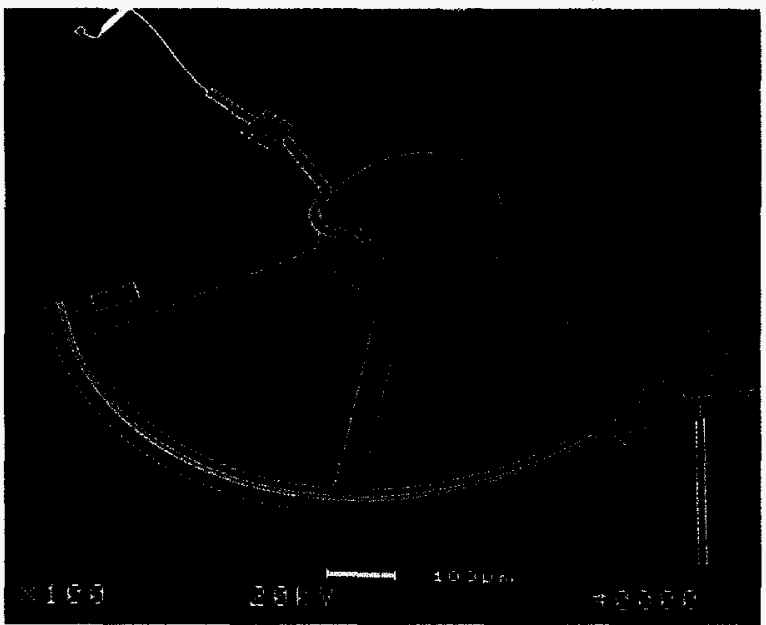

Figure 8 Micro-Flex Mirror Linkage System

Figure 8 shows the linkage system in the actuated position. The drive link, identified in Figure 5 has moved the push link through two fixed guides as shown. Figure 9 is a close-up view of the drive link and the two fixed guides.

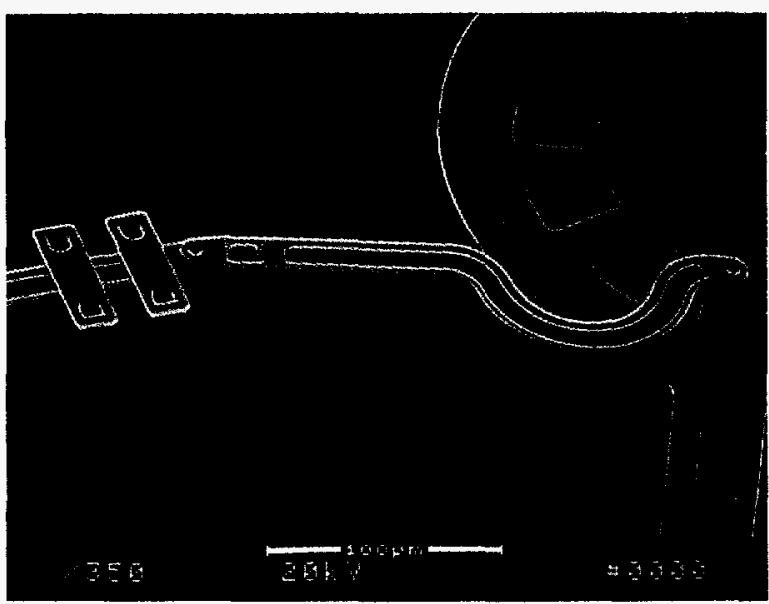

Figure 9 Drive Link

Figure 10 shows a fully actuated micro-flex mirror. The initial buckling load for the flexure, as designed, is $5 \mu \mathrm{N}$. Details of the analytical and numerical techniques used to determine the buckling and postbuckling response will be given in a later report.

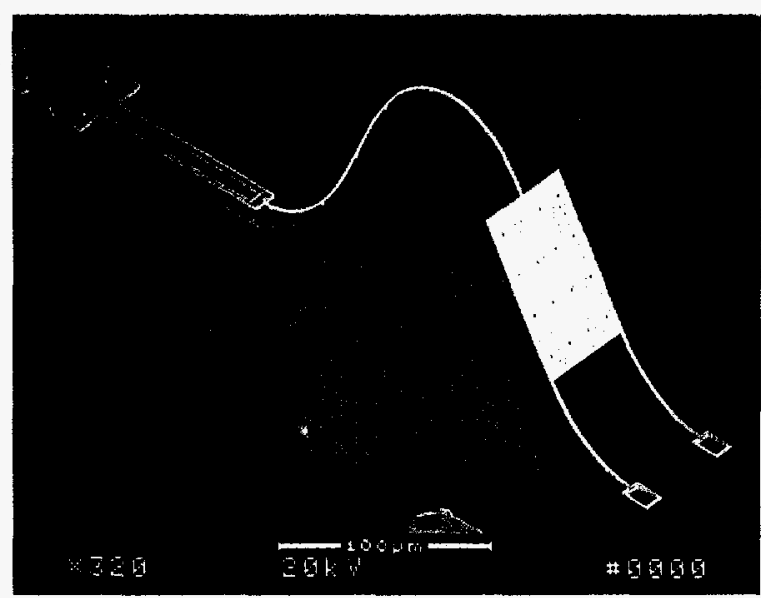

Figure 10 Actuate Position

Figure 10 also illustrates the connection of the mirror to the substrate through two anchor beams whose ends are fixed to the substrate. These anchor beams can be designed to provide a specific stiffness which in part determines buckling load and mirror actuate position. Other anchoring configurations of the micromirror are possible. The connections between the fixed anchor beams and the push link and flexure element can be replaced with pivoting hinges [9]. This may be desirable depending on the application since the critical buckling load for a pinned-pinned column is substantially lower than for a fixed-fixed column, where pinned-pinned and fixed-fixed refer to column boundary conditions. In fact, hinged connections will allow reorientation of the mirror to angles greater than $90^{\circ}$ from the substrate plane. Figure 11 is a close-up view of the underside of the $100 \mu \mathrm{m} \times 100 \mu \mathrm{m}$ mirror. Anti-stiction dimples can be readily seen on the mirror and flexure element. 


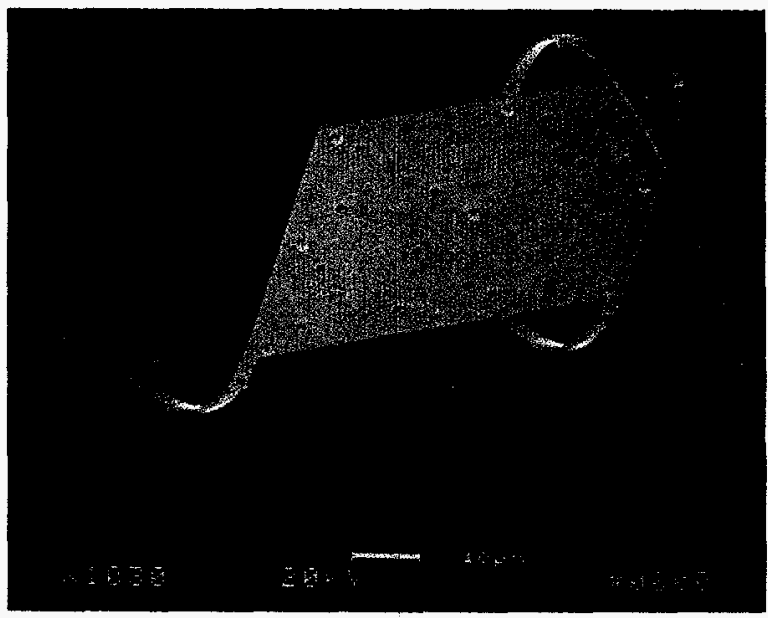

Figure 11 Backside of the Mirror

An examination of SEM's similar to those shown in Figures 10 and 11 allows us to estimate the strain in the curved flexure elements for several configurations of flexure length. SEM views from the side of the mirror and flexure permit measurement of radii of curvature. From beam theory, the maximum bending strain $\varepsilon$ in a beam is related to the beam curvature by equation (3), where $\rho$ is the radius of curvature and $c$ is the distance from the neutral axis to the outer most fiber. For a beam with a rectangular cross-section, $c$ is one half the thickness of the beam.

$$
\varepsilon=\frac{c}{\rho}
$$

A side view of the deformed state shown in Figure 11 indicates the radius of curvature for the flexure to be $37 \mu \mathrm{m}$. The thickness of the flexure is $1 \mu \mathrm{m}$, therefore $c=0.5 \mu \mathrm{m}$. Using these values, the calculated maximum bending strain is $1.3 \%$. Assuming a modulus of elasticity $E$ of $160 \mathrm{GPa}$, this would correspond to a maximum bending stress $\sigma_{\mathrm{m}}$ of $2.1 \mathrm{GPa}$. For comparison, fracture strengths reported for polycrystalline silicon [10] are in the $2.0-2.9 \mathrm{GPa}$ range. All test structures when returned to their original positions showed no signs of permanent deformation. These results are additional validation that the large strain capability of polycrystalline silicon makes it an excellent material for fabricating actuation elements that undergo large deformations.

\section{OTHER APPLICATIONS}

Structural instability has been used in a variety of macroscopic applications including electrical switching, thermostatic switching, and snap-through positioning mechanisms. The use of instability behavior in micro systems has been investigated by several authors primarily in the area of thermal buckling. A few of these projects are mentioned. Seki, et. al., [11] discusses a thermally buckled actuator, which uses a $2500 \mu \mathrm{m}$ fixed-fixed $\mathrm{Si}_{-} \mathrm{SiO}_{2-}$ Si beam to laterally displace $25 \mu \mathrm{m}$ and close a set of electrical contacts. Matoba, et. al., [12] describes a thermally actuated bi-stable polysilicon cantilever which actuates $+/-6 \mu \mathrm{m}$ for application to mirror positioning, microrelays, and non-volatile memory. Hälg [13] discusses fixed-fixed polysilicon beams to $40 \mu \mathrm{m}$ in length that laterally displace $1.5 \mu \mathrm{m}$. His application is to non-volatile memory and he suggests that capacitive actuation is advantageous. A thermally actuated microvalve is described by Lisec, et. al., [14]. This normally-closed valve is operated when a thermally buckled bridge structure displaces away from the valve orifice. All of the applications discussed above could also use the technique described for actuating the micro-flex mirror.

\section{CONCLUSION}

A procedure for raising planar structures up and out of their original plane of fabrication, with the application of forces generated only within the plane of fabrication, has been presented. This procedure has been applied to the design of a surface micromachined mirror system which can be reliably raised from its original plane of fabrication. Several configurations were fabricated and each device operated as designed. The use of a mechanically buckled structure to actuate a micromirror can also be extended to other applications as described above. However, based on the micro-flex mirror results, it appears that this technique can be used to assemble 3dimensional systems from the nearly 2-dimensional surface micromachined devices that can be fabricated from thin film depositions without the need for probe tip or other manual interventions.

\section{ACKNOWLEDGEMENTS}

The author would like to acknowledge J. Allen for CAD layout assistance, $M$. Polosky for testing assistance, A. Kilgo for SEM preparation, and the fabrication technicians in the Sandia Microelectronics Development Laboratory. This work was performed by Sandia National Laboratories, Albuquerque, NM, a multiprogram laboratory operated by Sandia Corporation, a Lockheed Company, for the United States Department of Energy under Contract DEAC04-94AL85000. 
References:

[1] T. H. Lin, "Integration of Micromirror and MixedSignal ICs for Optical Information Processing," Proc. SPIE, San Jose, CA, vol.2383, 1995, pp. 78-87.

[2] O. Solgaard, N. C. Tien, M. Daneman, M-H. Kiang, A. Friedberger, R. S. Muller, K. Y. Lau, "Precision and performance of polysilicon micromirrors for hybrid integrated optics," Proceedings SPIE, Volume 2383, Micro-Optics/Micromechanics and Laser Scanning and Shaping, San Jose CA, Feb. 1995, pp. 99-109.

[3] N. C. Tien, O. Solgaard, M-H. Kiang, M. Daneman, K. Y. Lau, R. S. Muller, "Surface-micromachined mirrors for laser-beam positioning," Sensors and Actuators A, vol. 52, pp. 76-80 (1996).

[4] S. P. Timoshenko, J. M. Gere, Theory of Elastic Stability, McGraw-Hill, NY, 1961.

[5] D. O. Brush, B. O. Almroth, Buckling of Bars, Plates, and Shells, McGraw-Hill, NY, 1975.

[6] J. W. Hutchinson, W. T. Koiter, "Postbuckling Theory,” Appl. Mech. Rev., vol.23, pp.1353-66, 1970.

[7] W. Fang, J. A. Wickert, "Post-Buckling of Micromachined Beams," Proc. IEEE Micro Electro Mechanical Systems Workshop, Oiso, Japan, 25-28 Jan., 1994, pp. 182-187.

[8] E. J. Garcia, J. J. Sniegowski, "Surface Micromachined Microengine," Sensors and Actuators A (48), pp. 203-214 (1995).

[9] K. S. Pister, M. Judy, S. Burgett, R. Fearing, "Mirofabricated Hinges," Sensors and Actuators A (33), pp.249-256 (1992)

[10] M. Biebl, H. von Philipsborn, "Fracture Strength of Doped and Undoped Polysilicon," Tech. Digest, $8^{\text {th }}$ Int. Conf. Solid-State Sensors and Actuators (Transducers'95), Stockholm, Sweden, 25-29 June, 1995, Vol. 2, pp. 72-75.

[11] T. Seki, M. Sakata, T. Nakajima, M. Matsumoto, "Thermal Buckling Actuator for Micro Relays," Tech. Digest, $9^{\text {th }}$ Int. Conf. Solid-State Sensors and Actuators (Transducers'97), Chicago, IL, 16-19 June, 1997,Vol. 2, pp. 1153-56.

[12] H. Matoba, T. Ishikawa, C. J. Kim, R. S. Muller, "A Bistable Microactuator," Proc. IEEE Micro Electro Mechanical Systems Workshop, Oiso, Japan, 25-28 January, 1994, pp. 45-50.

[13] B. Hälg, "On a Nonvolatile Memory Cell Based on Micro-Electro-Mechanics," Proc. IEEE Micro Electro Mechanical Systems Workshop, Napa Valley, CA, 1114 February, 1990 pp. 172-176.

[14] T. Lisec, S. Hoerschelmann, H. J. Quenzer, B. Wagner, W. Benecke, "Thermally Driven Microvalve with Buckling Behaviour for Pneumatic Applications," Proc. IEEE Micro Electro Mechanical Systems Workshop, Oiso, Japan, 25-28 January, 1994, pp. 13-17. 